TPR, 86 (6) 2015 doi:10.3828/tpr.2015.39

\title{
Supporting mindful planners in a mindless system: limitations to the emotional turn in planning practice.
}

\author{
Dr Natalie Osborne ${ }^{1} \quad$ Dr Deanna Grant-Smith ${ }^{2}$
}

Despite widespread acknowledgment within planning scholarship that emotion - both present in knowledge and a form of knowledge - is integral to lived experience and the judgement of planners, it is often sidelined within planning practice. The extent to which mainstream planning has been able or willing to accommodate emotions remains constrained and the emotions of planners and the public remain an unacknowledged but pervasive presence. Antonio Ferreira recently highlighted in this journal the importance of attending to emotions at the level of the individual planner through the concept of mindfulness. We argue this approach must be complemented by an acknowledgement of the structural and institutional limitations of including emotions in planning practice. Drawing from the emotional geographies literature to describe a social-spatial conceptualisation of emotion, we highlight ontological and practical tensions associated with the achievement of the 'emotional turn' and advance a more purposeful engagement with emotion in mainstream planning practice.

Keywords: emotion, emotional geographies, planning, policymaking, ontologies, silencing, other ways of knowing

\section{Introduction}

Since the turn against positivism in the twentieth century, scholars - including many planning scholars (for example, Davoudi, 2012; Friedmann, 2011; Sandercock, 1998a, Sandercock and Forsyth, 2005) - have critiqued the notions of objectivity and rationality at the heart of the positivist paradigm, arguing that other forms of knowing (lived, tacit, situated, embodied) are valuable and that pure objectivity and rationality are rarely, if ever, achieved. In this context emotion is understood as an ever-present but often unacknowledged influence on praxis. The 'communicative turn' in planning specifically challenged the positioning of planning professionals as neutral, technical experts engaged in rational and objective decision-making processes (Allmendinger and Tewdwr-Jones, 2002; Healey, 2009; Rydin, 2007; Sandercock,

\footnotetext{
${ }^{1}$ Dr Natalie Osborne is a Lecturer at Griffith University, School of Environment, Griffith University, G31, Gold Coast, Queensland 4222. Australia; n.osborne@griffith.edu.au

2 Dr Deanna Grant-Smith is a Lecturer at Queensland University of Technology, QUT Business School, Z Block Gardens Point, Brisbane, Queensland 4000, Australia; deanna.grantsmith@qut.edu.au Paper submitted August 2014; revised paper accepted February 2015.
} 
1998a; Saarikoski, 2002) and aimed to open participation to broader perspectives. Coupled with the growth in interpretivist approaches, which consider social and cultural dimensions of place (Davoudi, 2012) and the pragmatic stream of planning thought, which emphasises the situatedness, intuitive and emotional dimensions of planning practice (Healey, 2009; Hoch, 1984), planning has become, 'less and less about technical matters' (Friedmann, 1998, 250).

While this less technocratic approach has provided some opportunities for participants and practitioners to expand their knowledge of the positions and values of others (Healey, 1996) and created space for planners to recognise emotions, the accommodation of emotive and aesthetic forms of reasoning has arguably had a more limited influence on mainstream planning practice and decision-making. A commitment to the ideal of the rational, technical, objective expert (Throgmorton, 2003) has arguably influenced planners' willingness to actively engage with emotion, as it is perceived to decentre or diminish their professional standing or judgement (Allmendinger and Tewdwr-Jones, 2002). As such emotion may be 'overlooked by planners' (Buitelaar, 2009, 1062) as 'an unwelcome intrusion into a supposedly rational process' (Cass and Walker, 2009, 62) in which planners 'conceptualise themselves as professionals not emotionally engaged with the work' they do (Ferreira, 2013, 703). This is despite many planning scholars emphasising the emotional content of planning issues and the fact that engaging with emotion (particularly of applicants and opponents) is a key part of the daily work of practitioners (Baum, 1999; Fischer, 2009; Tewdwr-Jones, 2002).Emotion - both as a source of knowledge and as an influence on the decision-making and actions of planners - remains marginalised in mainstream practice and a 'wicked' problem that practitioners struggle to address (Vining, 1992).

A number of these issues were explored by Antonio Ferreira (2013) in a recent paper in this journal, in which he exposed the 'uncomfortable truth' (703) of the emotional nature of planning. Ferreira called for a more nuanced understanding of the importance and centrality of emotion in planning and the development of approaches to assist planners in dealing with emotion. Focussing on the emotions of the individual planner, Ferreira applied mindfulness theory as a practical means of equipping planners with the skills and capacity to deal with emotions at work. Other planning scholars have also problematised the framing of the rational, objective expert planner by exploring the importance of emotions, experience, thinking and judgement in planning practice (Hillier, 1995; Jones, 2013; Tewdwr-Jones, 2002) and emphasising the importance of planners becoming better equipped (through education and/or skills development) to work with emotions in planning practice (Fischer, 2009; Forester, 1987). 
Building on Ferreira's call to (re)acknowledge emotions in planning practice, we examine the structural (rather than individual) factors that shape the ways emotion is included within both planning practice and decision-making. We discuss why, despite decades of scholarly work on the topic, emotion remains marginalised in mainstream planning practices and rational frameworks continue to dominate. We argue that calls for individual planners to be(come) reflective (Schön, 1983), deliberative (Forester, 1999) and emotionally engaged must be accompanied by systemic, cultural and ontological changes within planning institutions and systems if they are to be effective. Building on the work of emotional geographers we advocate for a conceptualisation of emotion that considers its social and spatial dimensions. Recalling Ferreira's emphasis on the importance of mindfulness in individual planners, we consider how this mindfulness can be constrained by a 'mindless' system that still makes little room for emotion and the impacts of this on the practical achievement of the 'emotional turn' in mainstream planning.

\section{Embracing a social and spatial conceptualisation of emotion}

Emotion can be conceptualised in myriad ways. Ferreira (2013) suggests while more mainstream approaches to planning ignore emotion and its relationship to practice, psychoanalytical approaches which understand the importance of emotion 'take the planner to a dead end regarding what should be done to constructively integrate emotions in this practice' (713). Alternatives to a psychoanalytical conceptualisation of emotion include those that focus on affect and embodiment (for example, see Daya and Wilkins, 2013; Watkins, 2011). However, because our scale of analysis is the structural rather than individual level, in this paper we draw primarily from the emotional geographies literature to conceptualise emotion and explore its implications as a practical consideration in planning.

Emotion is often conceptualised as being individual and internal. However, emotional geographers contend that emotion is socially and spatially constructed. Ahmed (2004), for example, proposes an 'outside in' model of emotion, arguing that, 'rather than emotions being understood as coming from within and moving outwards, [they] come from without and move inward' (9, emphasis in original). Emotion, then, is understood as both relational and as emerging from social and spatial interactions (Nairn and Higgins, 2011; Zembylas, 2011). This construction is iterative. Thus because emotion contributes to the creation and constitution of spaces (Pritchard et al., 2002) and shapes 'not only what the world is, but also how it comes to be this way' (Wright, 2012, 1115), it can only be fully understood within its spatial and social context (Davidson and Milligan, 2004). Emotion is embodied, spatially and temporally constituted, 
shapes and is shaped by relationships between people and between people and places and is part of how we construct and know places, social and power relations and structures (Bondi, 2005; Davidson and Milligan, 2004; Heimtun, 2010; Sultana, 2011).

Emotion is therefore critical to understanding place and spatial issues. Emotional geographers have devoted considerable attention to understanding the construction and experience of emotion by and through space and place. As such, this body of work differs from other, more individually-focused approaches to emotion and offers a lens to analyse emotion as a social, spatial and structural phenomenon and to focus on the ways emotion is shaped by power relations, local contexts and place.

Emotional geographers have explored the ways in which emotion is considered important to, or a source of, knowledge. They argue that not only is emotion present in traditional scientific pursuits but that emotion itself is a site of knowledge and a fundamental component of the construction of our experiences (Jones, 2005). Emotions in this context can be understood as, 'ways of knowing, being and doing in the broadest sense' (Anderson and Smith, 2001, 8) and can become transformative knowledge (Ahmed, 2004).

Emotional geographers contend that the way (or if) emotion is expressed is influenced by social and spatial contexts (Hepworth, 2005), which has a range of implications for planners seeking to engage with emotion. For example, Thien's 2005 study on the spatiality of intimacy in island communities in the North Sea highlighted social and spatial influences on emotion and behaviour. Thien gives the example of 'Judy', who longs to buy a bicycle yet hasn't because she fears stigma in a place where she is both visible and familiar. Thus even policies that seem devoid of emotive or sensitive content, such as policies promoting active transport, may be affected by the emotional geographies of the target community/place. Without an understanding of how emotion can shape actions within a particular social-spatial context-such as how Judy's transport decisions are affected by familiarity, visibility and the need to conform-planners may be missing something critical to the achievement of desired outcomes. In the following sections we consider the place of emotion in mainstream planning practice and the barriers to it becoming more visible and better integrated into planning decision-making.

\section{A place for emotion in planning systems}

As previously discussed, planning has, to some extent, moved away from its technocratic roots. Unilateral decision-making on planning and related policy matters - even when these decisions are seen to be based on sound information and have satisfactory outcomes - is no longer 
acceptable to the community or considered good practice. Public involvement has become an expected feature of planning and the success of consultative efforts in including the views of stakeholders is often a key measure of overall success (Cameron and Grant-Smith, 2014). This shift has been described as the 'communicative turn', where the primary role of a planner is to facilitate deliberative processes (Fischler, 2000). This is the most visible and widely accepted 'place' for emotion in planning practice, as it is expected that the public will express emotion when participating in public engagement processes. Despite this shift it remains difficult to incorporate the emotions expressed by participants into decisions. Similarly the emotions of practitioners remain placeless in 'good' planning.

Although it is generally recognised that the planning process is complex, untidy and politically influenced and that it is important to incorporate input from collaboration with stakeholders (whose views are informed by a range of factors, including emotion) into planning, the public and planners alike are expected to limit input into scientific, objective and/or numerical evidence. Both McGuirk (2001) and Tewdwr-Jones and Thomas (1998) have found that to achieve this synthetic ideal planners subtly change community input through processes of sorting, prioritising and translating and in doing so privilege the rational and technical aspects of submissions and discount or downplay other forms of knowledge and expression. It is understandably difficult for practitioners to work with emotions in practice, as they operate within 'a professional milieu that constantly reminds them that their own emotional reactions... are not permissible in a process which must be well-documented, traceable and defensible (often in a court of law)' (Vining, 1992, 7-8). Subjective forms of input, like emotional and affective responses formed in relation to values, connections to place and community, lived experience, context and history (which emotional geographers argue are crucial to the construction of experiences) may be dismissed as irrational, irrelevant, baseless or as 'outlier' data with no place in the decision-making model. This objective and positivist orientation to planning and policy acts on the idea that:

"variables such as ideas and values are to be eliminated or minimized to the degree possible. In those cases where they prove unavoidable, efforts should be made to find quantitative indicators that can stand in for them" (Fischer, 2003, 22).

Such approaches discourage, 'the public's expression of emotional values when presenting their view' (Magill, 1991, 16) and if that view is inextricably linked to emotion and values, there may be no space for it at all or its expression confined to predetermined, 'stock' categories. Despite the legitimate role that emotional arguments and knowledges have in planning and policy 
discourse (Freiberg and Carson, 2009) and many planning scholars calling for planners to be empathetic and sensitive to the emotions of the people they are planning for and engaging with (Forester, 1999), there remains a dominant focus on 'objective facts' in mainstream planning, which emphasises the need to adopt processes of, 'vigilant policing...to keep emotion from creeping in where it does not belong' (Maroney, 2006, 125). Approaches to planning and policymaking which reinforce this irrationally synthetic rational ideal marginalise emotion and values behind the rhetoric of process-driven objectivity. It is evident that not only is quantifiable, scientifically-derived information valued more highly than other forms of knowledge (Head, 2010) but that considerable lengths are often taken to exclude emotion and knowledges founded thereupon.

Countering this, emotional geographers join their voices with planning scholars including Baum (1999), Forester (1999), Fischer (2009), Sandercock (1998b), Healey (2010) and Hillier (1995) in arguing that emotion and other diverse knowledges have a place in planning as they can assist in understanding issues and catalysing change. For example, Farbotko and McGregor (2010) reflect on emotion at the Copenhagen Conference of Parties in 2009, when a delegate from Tuvalu became explicitly emotional during his statement. This subversive act deviated from the usual 'rational', detached tone of these events and highlighted the need to explore how 'science and emotion combine with reformist or radical potential' (Farbotko and McGregor, 2010, 164). In another climate change example, Gorman-Murray (2010) argues that focusing on the local, situated, relational ways climate change will be experienced might help mitigation efforts. However, although these examples highlight the impact and catalytic, transformative potential of emotion in planning practice, they also underscore the continuing tendency for mainstream planning to exclude emotion.

\section{The implications of silencing emotion}

Although mainstream models of planning rarely leave room for emotion - and are often structured around processes intended to exclude it - this does not mean that these processes, or the people engaging in them, are emotionless. Indeed, although planning relies upon subjective, contextual judgements and decisions made by individuals, decisions are often 'discussed as if politics and morals were mutually and necessarily exclusive subjects' (Gillroy and Bowersox, 2002 , 2). By silencing emotion, two key problems emerge. The first is that this silencing does not make emotion absent, it renders it and its influence, 'unknown, uncertain and unspoken'(Ferreira, 2013, 712-13). When emotion is explicitly silenced it will still be experienced, but perhaps in unexpected and deleterious ways; practitioners may find themselves 
without tools to deal with manifestations of emotion and the ramifications of silencing emotion may damage the success of the overall policy/plan. This omission is particularly problematic in planning processes dealing with complex social and environmental issues with affective or emotional significance or highly contentious issues where the conflict may be driven, at least in part, by emotional, affectual and values-based divisions.

Good decision-making requires the acknowledgement of conflicts, paying attention to emotional and psychosocial factors and expanding the scope of discussion (Goldman, 2004). Thus policy and plan making 'has no choice but to traffic in emotions' (Bandes, 1997, 7); technical or scientific approaches that exclude emotion can have significant implications for policy implementation (Grant-Smith, 2011). Indeed, policies and plans are more likely to be adopted if, in addition to gathering and presenting 'objective' evidence, they recognise and adequately respond to intangible things like emotion, symbols, values and faith (Freiberg and Carson, 2009) as important parts of the planning and policy landscape. Indeed, Morgan and Grant-Smith's (2014) analysis of the public rejection of recycled water proposals found that emotion can perhaps be more influential than science in shaping public opinion.

The second problem is that silencing may result in the exclusion of valuable forms of knowledge because they are 'tainted' with the mark of emotion; the absence of local, situated, contextual, traditional and embodied knowledges leads to less informed policy and plan making. This rejection and concomitant ignorance affects our understanding of problems, how they are experienced, how they relate to other problems and the potential range of policy impacts, including on the people tasked with their implementation. For example, drawing from research on the Foot and Mouth Disease (FMD) outbreak in Cumbria, Convery et al. (2008) argue that local, situated knowledges are, 'essential to the formation of effective and sustainable recovery policies and initiatives', but that survivors of disasters are rarely given the opportunity to contribute their experiences and knowledges (10). They found that marginalising these knowledges contributed to the scale of disaster and trauma experienced during the FMD outbreak, as using local knowledge and practices could have contributed to better management, reduced unnecessary culls and prevented some upsetting mistakes from occurring. Indeed::

"without situated knowledge which is local and partial, in the sense that it has a perspective based on experience, authorities cannot 'see' how to act, and this is one of the hardest lessons in the wake of disasters where the actions of recovery agencies have the potential to bring relief, but also to retraumatise and make things so much worse" (Convery et al., 2008, 87 emphasis in original). 
Ignoring practical contextual knowledges and other ways of knowing - especially those marked with emotion - can have unintended impacts on policy development and implementation. Yet, even with the best intentions participatory processes designed to elicit a wide range of input are likely to encounter both ontological and practical difficulties when attempting to accommodate emotional input into decision-making. These challenges and their impacts on planning systems and planners are the focus of the remainder of this paper.

\section{Exploring the ontological tensions presented by the emotional turn}

For an emotional turn to occur, the ontological frameworks shaping the construction of knowledge and emotion must be problematised. The following section explores the dualistic ontological construction of emotion and reason and considers how this construction privileges certain knowledge systems and the subjugation of others. This construction continues to underpin planning institutions and decision-making frameworks, despite widespread critique and attempts by many individual planners to be more inclusive in their work.

\section{The double edged sword of dualisms}

Dominant Western constructions of knowledge centre reason, rationality, objectivity, neutrality and detachment as routes to knowledge. As previously discussed these constructions are prominent within planning discourse. Emotion, conversely, has long been constructed as an impediment to reason, inherently irrational and anathematic to the objectivity, neutrality and detachment necessary for knowing (Ahmed, 2004). The philosophical constructs of dualism divided body and mind and in doing so relegated emotion to the body and reason and knowing to the mind (Anderson, 1997; Mysak, 2010). 'Reason', defined in opposition to emotion, has been the purview of science, research and academia in the Western world and as such emotion has been marginalised from knowledge production, dismissed as something that, 'clouds visions and impairs judgement' (Anderson and Smith, 2001, 7). In planning, emotionless objectivity has been the marker of reliability and emotion an impediment (Vining, 1992).

Equating reason with the mind and emotion with the body has served as a way not only to privilege certain forms of knowledge, but also to privilege the people associated with those forms of knowledge. Emotion - seen as something messy, embodied, divorced from reason, irrational, natural and/or instinctual - has, in the past, been associated with women, the poor and with people of colour, whereas clean, detached, civilised reasoning has been associated with elite white men on the 'mind' side of this dualism (Anderson, 1997; Wright, 2012). This construction has been used to justify the domination of (traditionally) educated white men over Others and 
has been used to deny other ways of knowing recognition, power and influence (Ahmed, 2004; Mysak, 2010).

Feminist thinkers, critical race theorists, critical geographers, Indigenous epistemologists, poststructuralist historians, philosophers of science, planning scholars and emotional geographers have challenged this dualism at the ontological level, problematising the divide between mind/body, male/female, white/people of colour and reason/emotion on many fronts (Morrison, 2010; Sandercock and Forsyth, 2005; Wright, 2010). It has been argued that the detachment and neutrality of science is a myth, as science does not exist in a vacuum and is necessarily shaped by political, social and cultural contexts. Where all knowledge is considered biased, there is little basis for disregarding or excluding knowledges that are marked by emotion (Saarikoski, 2002, 3). Others challenge the oppositional construction of reason and emotion, arguing that emotions are 'integral parts of' (Knopp, 2007, 53) and 'enframe' (Jones, 2005, 205) reason and rationality. Bondi $(2005,236)$ argues that, 'our feeling states and our thinking are closely intertwined' and that the 'restraint' and 'detachment' valued in the positivist paradigm are actually forms of emotion themselves. Others have disputed the dualistic thinking that maps emotion onto women's bodies (and other Othered bodies) and reason onto (white) men (Mysak, 2010), which has served as a way to give certain people privileged access to knowledge and power and to justify the oppression and silencing of Others (Gerber, 1997; Mysak, 2010). Importantly, this divide is a cultural one; it doesn't exist in some non-Western epistemologies. In Hawaiian epistemology the seat of knowledge is, 'the stomach or nu'au. The na'au for Native Hawaiians is the site for both feeling and thinking.... Our thinking body is not separated from our feeling mind' (Meyer, 2008, 223).

Sandercock (1998b, 217) argues that planners should adopt and be trained in, 'an epistemology of multiplicity', in order that they be aware of the embodied, experiential and situated nature of knowledges and how they are affected by power and culture. She suggests, 'A good planner will be sensitive to all these ways of knowing, without privileging any one of them' (Sandercock, 1998b, 217). To this, we add that a good planning system must adopt an epistemology of multiplicity. In order for other ways of knowing to gain traction in planning practice and decision-making, focus cannot be only on the training, behaviour and practices of individual planners, but also attend to how the system within which they operate - a system that, as argued by emotional geographers, itself influences the emotions of individuals - can be changed to allow the integration of emotion and other forms of knowledge to appropriately influence decisions.

\section{Power, identity and 'being emotional'}


The dualistic positioning of rationality and emotion as opposites is not power-neutral. Given the social and spatial conceptualisation of emotion adopted in this paper, it is also important to consider how emotion and the way it is expressed and perceived is shaped by identity and power relationships. Some individuals have the licence to express a certain range of emotions without being dismissed as, 'being emotional' or being penalised for expressing them. This is a function of the privileging of certain identity groups and gendered and racialised expectations. For example:
"women litigators are penalized for displaying emotions such as anger and aggression, even though these feelings are expected of men in this heavily male profession...emotional norms, like occupations and organizations themselves, are intrinsically gendered in ways that perpetuate inequality between men and women employees" (Wingfield, 2010, 251).

As such, deciding what (or who) is rational and what (or who) is not, may also be a decision influenced by emotion, mores and culture. It is by this logic that white men are more likely to be perceived to speak in a detached, literal, calm way without overt emotion, whereas women and people of colour are more likely to be perceived to speak in a more emotionally-marked way, with passion, metaphor and variation of tone and gesture (Young, 1995), marking them less rational and thus less worthy to be heard.

Despite critiques from multiple quarters this perception remains prevalent, if unspoken, in planning despite the communicative turn. While the communicative turn challenged and arguably had an influence on planning practices and legislation, its lessons have not been widely used to challenge thinking at the ontological level. Indeed, the deliberative model often drawn upon in the communicative turn has also been critiqued as privileging rationality and reason, to the detriment of other forms of thinking, knowing and expressing (Davies et al., 2012). As such, the tendency remains to 'falsely identify objectivity with calm and absence of emotional expression. Expressions of anger, hurt or passionate concern discount claims and reasons they accompany' (Young, 1995, 139). Ferreira (2013, 710) likewise acknowledges that emotion and being emotional are generally considered negatively and that planning professionals seek to avoid or limit emotional expression because it is associated with 'foolishness'. As a result emotions are most 'likely to emerge only when individuals actually break down' (710), thus being emotional is perceived as incompatible with professional conduct and can diminish the power and privilege that comes from professional status. 
For emotion to be made visible and authentic and for its presence and expression to not delegitimise the person feeling and expressing it, we need to critically consider the ways emotion and people deemed to be 'emotional' has been constructed and why. We need to consider how structures of power and privilege have been created and reinforced by a dualistic construction of reason and emotion where both traits have been gendered and racialised. It also requires the rethinking of the nature of 'professionalism' in a way that does not exclude emotion or conflate emotion with incompetence. This is particularly difficult, especially when one has benefitted from presumed rationality on the basis of gender and/or race and/or professional status.

\section{Practical tensions associated with an emotional turn}

While it is broadly acknowledged that emotion influences decisions and judgements, the value or credibility of overly emotional contributions is often questioned and decision-making processes are structured to exclude them. Thus, although the communicative turn in planning enshrined concepts of public involvement (Healey, 1996), it remains the case that there is only space in planning for a limited range of emotions, in limited contexts. Evidence of emotional responses can be used to dismiss concerns as irrelevant or to strategically discredit those expressing them (Cass and Walker, 2009). This is a powerful motive to attempt to hide or deny emotion within more 'rational' contributions (Grant-Smith, 2011). As a result there remain a number of practical tensions to be worked through, including the unspeakability of certain issues and emotions and recognising the difficulties planners face in dealing with the emotions of stakeholders. In addition, as Ferreira and others have noted, the challenges planners face in dealing with their own emotions - especially given the pressure to mask emotion to preserve professional standing and identity - must be recognised.

\section{Making space for Others and Othered emotion}

Planners are often tasked with engaging stakeholders, but despite an increased focus on developing facilitation and negotiation skills within some planning courses, many may lack the skills needed to do 'emotion work'. In the course of their daily work planners are likely to encounter a range of emotions in diverse manifestations - indeed, this is expected and accepted, particularly in public hearings or similar engagement contexts - but even planners equipped to deal with emotion may find it impossible to formally account for them within decision-making

\footnotetext{
${ }^{3}$ Indeed, emotions may be, 'inchoate and unmanageable to most people' (Tuan, 1977, 202), not just planners.
} 
processes. Because the ideal of rational planning is founded on objective and quantifiable decisions, how the emotions of planners and participants can be incorporated into planning decisions is often unclear. The dilemma of 'how to deal with passion' requires recognition that 'in many situations, planners are dealing as much with people's passions as with their own earnest technical predictions' (Sandercock, 1998b, 7). Yet planners may be explicitly instructed to not be moved or affected by passion or anger and to remain impassive and neutral at all costs (Tewdwr-Jones, 2002).

This approach fails to recognise that for some planning issues emotion is unavoidable; an example of these is what Grant-Smith (2011) has termed unspeakable problems. These unspeakable problems are wicked problems (Rittel and Webber, 1973) with deeply emotional connotations, including those shaped by passionately held values and beliefs or with a strong affectual component, such as repulsive issues. Often unspeakable problems (and the emotions themselves) might be considered 'taboo' or not suitable to be discussed in 'polite' company. Examples include planning decisions for controversial or unpopular land uses such as brothels (Prior and Crofts, 2012), funeral parlours (Hillier and Gunder, 2005) and sex shops (Papayanis, 2000). The inherently provocative, unspeakable nature of these problems limits their ability to be discussed in the rational, considered, objective way that conventional planning demands, illustrating a limitation of conventional approaches. Planners and the public alike often struggle to articulate their feelings about these issues. Sometimes emotions may be so complex and deepseated that they are not only unspeakable, they may be to an extent unknowable; felt, but not cognitively acknowledged or expressed. Emotions may be, 'so ancient and deeply ingrained that they are largely invisible' (Bandes, 1997, 2) and because emotions are marginalised from practice and 'because they see little of it among their colleagues' (Vining, 1992, 28), practitioners may view their own responses as problematic, out of place and irrational. This may undermine their confidence in their professional judgement and make them more inclined to doubt the judgement of others should they express emotion. Given that, as previously discussed, the expression of emotion is shaped by context, it is also important to consider how it is framed and the discourses and symbolism invoked in both the expression of emotion and in the planning structures, systems, instruments and decisions underpinning them (Buitelaar, 2009). Further, it must be emphasised that emotion is not always positive; some emotions are harmful and destructive.

An example of a highly emotive issue with unspeakable components can be found in planning for mosques in Australia. Applications for religious infrastructure for an Othered group are often 
met with considerable community opposition and the planning process can be an outlet for racism and xenophobia (Sandercock, 2000; Vahed and Vahed, 2014). In Australia, many mosques:

"are located on the periphery of the metropolitan area, or in industrial zones, remote from their worshippers, inaccessible by public transport, and often adjacent to incompatible land-uses such as garbage tips, or storage depots, or 'big box' retail outlets"(Sandercock, 2000, 19).

The justification for this siting often rests on claims about noise, traffic, parking, incompatibility of land use, even increased crime, yet this may mask other reasons less acceptable or justifiable on planning grounds (Sandercock, 2000; Vahed and Vahed, 2014). In 2002, an Islamic group had their proposal to construct a mosque in Annangrove (Sydney, Australia) rejected by the local council after significant community opposition (Dunn, 2004). Ultimately this decision was overturned after the group successfully appealed to the New South Wales Land and Environment Court, who found no planning grounds for refusal (Dunn, 2004; Dunn, Klocker and Salabay, 2007). Those who opposed the development stressed that their objections were not grounded in racism; their formal objections were framed to highlight objective planning concerns regarding the local area's character, demographics or potential problems with parking (Dunn, 2004; Dunn, Klocker and Salabay, 2007). Despite the deliberate use of the planning language and frames one can perceive 'fear of the other' (Sandercock, 2000, 21) and change, the idea of Muslim non-belonging and what Dunn $(2004,334)$ has dubbed 'a discourse of cultural absence' undermining the citizenship and belonging of the Muslim population. Outside of formal planning processes, community objections grounded in anti-Islam sentiment were more visible; for example, the local mayor implied that the development presented a safety issue for girls and women in the area and that the increased presence of Muslim men was somehow a threat to them (Dunn, Klocker and Salabay, 2007).

Understanding 'fear of the other' (Sandercock, 2000, 21) can be enhanced by a social-spatial conceptualisation of emotion, one sensitive to both the social and cultural factors shaping responses and how spatial, visible markers of difference and of change, like a mosque in a suburb that has been dominated by Christianity since colonisation by Western Europeans, can be sources of considerable fear and anxiety for some. This does not mean that planners or the planning system, need to consider those emotions as strong grounds for denying approval; making a place for emotion in planning processes does not mean endorsing or acting on every emotion felt and expressed. However, when emotion remains excluded, potentially harmful 
emotions/sentiments are not brought to light and cannot be challenged, assuaged or moved past. Approval for building a mosque despite objections rooted in fear of the Other may be considered a positive social outcome. Likewise, rejection of the development in response to community concerns may be considered a reflection of the increased influence of community voice in planning decisions. However, in both cases unless space is provided for emotional deliberation the anti-Islam sentiment, fear and anxiety underpinning many of the objections will remain. Acknowledging difficult and emotional issues is imperative to productively addressing them (Baum, 1999).

Sandercock (2000) suggests engagement processes that actively allow for emotions to be shared can be a strategy for moving past these kinds of conflicts around difference and fear of the Other. The potential of storytelling for making space for and encouraging the expression and working through of emotions in planning practice has been highlighted by planning scholars (Forester, 1999; Sandercock, 2000; Throgmorton, 2003; van Hulst, 2012). Such approaches can be both cathartic and transformative as they support the discussion of topics that can otherwise be difficult to discuss and can illustrate values, attitudes and contexts (Forester, 1999; Saarikoski, 2002; Sandercock, 2001; Throgmorton, 2003). Storytelling also often comes naturally to participants in planning processes, who may have a preference or tendency to express themselves through stories imbued with rich emotional content (Saarikoski, 2002). Encouraging these kinds of contributions can support participation from a more diverse range of participants (Sandercock and Forsyth, 2005). However, given the vulnerability of participants in such approaches, Cameron and Grant-Smith (2005) advocate the use of layered engagement processes which provide protected spaces in which groups which are usually marginalised from planning and decision-making processes first work to develop their own positions before embarking on broader participatory activities. It is also important to acknowledge that the expression of emotion is shaped by context and 'unspeakable' emotions may be expressed and masked by others. Such a layered approach may allow these emotions to be worked through before they are shared in a broader setting.

Empathy on the part of an individual planner, uncritically recounting lists of emotions expressed or cataloguing stories shared is insufficient to effectively incorporate emotional contributions into decision-making (Bondi, 2005; Burman and Chantler, 2004; Fischer, 2009). Where storytelling is used, practitioners need to consider not only the framing and telling of stories (Throgmorton, 2003) but also the construction of emotion reflected in them, factors shaping the way they are experienced and expressed, the implications of power, privilege and marginality and 
what they suggest about the social and spatial landscape to which they relate. Thus, while practices like storytelling may encourage the expression of emotion, without systemic changes that allow for this data to be valued alongside more quantifiable forms of knowledge, those stories and the emotions they contain may not be incorporated in any meaningful sense, remaining, 'uncoupled from other activities like formal decision-making...or the making of concrete plans' (van Hulst, 2012, 305). Practitioners may have done considerable emotional work, yet find themselves with data that the system will not adequately recognise.

\section{Managing 'surplus' emotion}

While the issues associated with engaging stakeholders in the development of plans and policies are well advanced in the planning literature (e.g. Forester, 2012) the emotional realities associated with implementing plans and policies are less often acknowledged. Those responsible for implementation are sometimes termed 'street level bureaucrats' (Lipsky, 2010, xi) who can have a significant role in influencing how polices and plans are enacted. This is because their work embodies a paradox: highly scripted work to achieve objectives juxtaposed against considerable improvisation and responsiveness to individual cases. However, the emotions influencing responsiveness are still largely deemed 'surplus' and a personal issue or problem is to be subsumed under an impassive professional persona. Tewdwr-Jones (2002) recounts his difficulties maintaining a professional demeanour in the face of anger, frustration and the offer of a bribe from an applicant; he had been advised by his superior 'not to react on any count' (76) and any expression of his own feelings (including sympathy for the applicant), was curtailed by the professional persona he had to adopt. This charge to remain impassive and unaffected overlooks the significant effect that being subject to the strong emotions of others can have on practitioners. The social-spatial understanding of emotions recognises that the emotions experienced by planners are not merely their own individual experience and responsibility. Rather, they are connected to and partially constructed by, their experiences with others and the institutional, organisational, political and spatial context in which they work.

As such, it is vital to consider the emotional impact of conflicting personal values and professional roles and expectations, like developing or implementing a plan or policy one personally disagrees with (Ferreira, 2013; Grant-Smith, 2011). Further, the emotions of practitioners may be quite different to the emotions of others engaged in the process (Vining, 1992), which exacerbates the difficulty of dealing with and managing emotions in practice. The rational-technical structures shaping planning also belie the important role emotion plays in decision-making and implementation, particularly in high-stress, contingent or contextually- 
dependent situations (Jones, 2013) and as previously discussed, the façade of the rational planner remains important to maintaining the credibility of planning as a both a process and a profession.

Ferreira $(2013,705)$ argues that the 'discretionary judgement and subjective advice' which forms a large part of the planner's role is 'likely to be emotionally draining', yet due to the silencing of emotion and the value placed on rationality and objectivity this emotion work is unacknowledged and undervalued. This may occur in planning activities like community festivals (Jones, 2013), as well as in more mundane daily planning practices. For example, Grant-Smith (2011) discusses the negative reactions of enforcement officers on being required to enforce emotive and politically charged policies associated with managing sewage discharges from recreational boats, because dealing with emotional boaters and being branded 'poo police' was not something they had 'signed on for'.

In another example, Convery et al. (2007) explore the emotional impacts on frontline workers (generally public servants seconded from other departments) during the Cumbria FMD outbreak. The emotions of the workers were rarely considered; they were conceptually excluded from 'victim' category and considered, 'impervious to traumatic experience'. However, disaster workers can also be victims of disaster and the emotional impact of being frontline bureaucrats in a crisis should not be underestimated. Convery et al. (2007, gave an account of a field officer who felt, 'morally compromised', angry and who experienced, 'flashbacks and suicidal thoughts and recurring traumatic images' due to their work implementing policies. This clearly points to the need for the emotional impact of plan and policy implementation to be acknowledged and integrated into decision-making.

In addition to considering how emotions affect decision-making and implementation, it is important to consider how those emotions are constructed and experienced through their social and spatial contexts. Psychoanalytical approaches are important and valuable but only take us so far; the institutional, structural, social and spatial influences on emotion and the way in which emotion moves from the outside in, need to be better considered. Despite many scholars acknowledging the importance of emotion in engagement, other ways of knowing and epistemologies of multiplicity, and despite the role emotion plays in the thinking and actions of planners, institutional cultures and expectations of detached professionalism continue to curtail the expression of emotion and limits its visibility and influence in decision-making. 
Beyond its use as an engagement tool, storytelling used in institutional contexts can also encourage planners to develop skills in dealing with their own vulnerability and emotions. Stories have particular value in practitioner interactions and in changing institutional cultures, and sharing practitioner stories can make space for and normalise emotion in planning practice (Forester, 1999). However, Forester (1999) notes that planners need professional permission and space to share these stories with each other.

\section{Advancing the emotional turn}

"It is a common tendency to regard feeling and thought as opposed, the one registering subjective states, the other reporting on objective reality. In fact, they lie near the two ends of an experiential continuum, and both are ways of knowing" (Tuan, 1977, 10).

Despite the ubiquity of emotion in planning and the recognition of its importance by both planning and geography scholars, it is rarely identified as a resource or 'source of intelligent judgement about complex choices' (Hoch, 2006, 372) in mainstream planning practice. In many situations, it remains the case that emotion is considered superfluous, contributing to bias and the distortion of rational reasoning and for that reason must be controlled, tamed or excised (Hoch, 2006; Vining, 1992; Fischer, 2009). However, in order to plan effectively planners 'must be able to respond to others' ideas and to their passions: their fears, suspicious, distrust, [and] anger...[b]ut this is emotion work that planners are poorly trained to do' (Forester, 2012, 256). In mainstream planning participants and planners are expected to ignore or not feel, emotion and to limit the knowledge that decisions are founded on to objective facts, and there remain structures in place that enforce emotion's exclusion (Vining, 1992). Despite repeated calls for the acknowledgement of emotion in planning and for planners to develop the skills and mindfulness to accommodate emotional contributions, dominant constructions of rationality and legitimate knowledge leave little space for emotion and current decision-making processes render silent, invisible and unspeakable those emotions that are inextricable from the issues and people involved. Creating more space for emotion in planning systems and structures is thus critical for advancing the emotional turn.

However, empathy with those emoting and increasing the space for the expression of emotion in practice does not mean it is to be treated uncritically. There are dimensions of power, privilege and identity to emotion and certain emotions may be considered acceptable from some people and not others, or may be given more weight than other emotions or the emotions of Others, depending on who is expressing them and how. Further to this, following the lead of emotional 
geographers, we argue that the social and spatial construction of emotions (of both the public and of practitioners) should be considered in addition to the emotions themselves. The mindfulness of individual planners must be able to feed into, challenge and shape what may currently be considered a relatively 'mindless' system with little place for emotions and other ways of knowing. In this paper we have sought to provide additional critique and discussion around Ferreira's argument that acknowledging and responding to emotion is a critically important enterprise for planning and for planners. We advanced an 'emotional turn' which positions planning, at all stages from plan making to plan implementation, as an inherently emotional activity. We support Ferreira's $(2013,709)$ assertion that:

"Planners should know that emotions are likely to deeply influence their practice... [and] abandon the common understanding that when someone acts or thinks emotionally, the quality of professional performance to be expected is necessarily low.

However, we recognise the complexities associated with this shift and have sought to underscore the ontological tensions that encompass what mainstream planning accepts as knowledge and how that acceptance is bound in notions of rationality attached to certain identity markers.

Like Ferreira we also recognise the practical complexities associated with this shift and the lack of tools, space and skills for processing and accommodating emotional expression. Ferreira $(2013,714)$ proposes mindfulness as a tool to support planners 'to open up greater (not less) access to one's emotions and to facilitate their integration in professional practice' in an effort to 'acknowledge emotions fully, understand how they influence the decisions we make, use them with maturity and ethical integrity and allow ourselves to be deeply moved by them when appropriate'. We have likewise stepped outside extant planning approaches to inform our understandings of practical engagements with emotion through the emotional geographies literature.

Resolving the tensions identified in this paper will be challenging and it is not a task all planners and policymakers are well-equipped to address, but work done in other fields, such as emotional geographies and political science among others, may inform these efforts. Storytelling is widely acknowledged as a useful tool to advance the emotional turn in planning, but without clear and meaningful ways to incorporate stories and the emotions they express into mainstream planning processes and decision-making, planners may find themselves with a wealth of knowledge they have no recognisable or defensible way to act upon. While there are more challenges and opportunities presented by this shift than have been explicitly addressed in this paper, we hope 
that by highlighting these tensions we can further the discussion (re)started by Ferreira and in doing so, direct collective efforts toward finding ways to advance the emotional turn in planning.

\section{References}

AHMED, S. (2004), The Cultural Politics of Emotion, New York, Routledge.

ALLMENDINGER, P. and TEWDWR-JONES, M. (2002), 'The communicative turn in urban planning: unravelling paradigmatic, imperialist and moralistic dimensions', Space and Polity, 6, 524.

ANDERSON, K. (1997), 'A walk on the wild side: a critical geography of domestication', Progress in Human Geography, 21, 463-85.

ANDERSON, K. and SMITH, S. J. (2001), 'Emotional geographies', Transactions of the Institute of British Geographers, 26, 7-10.

BANDES, S. A. (1997), 'Empathy, narrative and victim impact statements', University of Chicago Law Review, 63, 361-412.

BAUM, H. S. (1999), 'Forgetting to plan', Journal of Planning Education and Research, 19, 2-14.

BONDI, L. (2005), 'The place of emotions in research: from partitioning emotion and reason to the emotional dynamics of research relationships', in Davidson et al. (eds), 231-46.

BURMAN, E. and CHANTLER, K. (2004), 'There's no-place like home: emotional geographies of researching 'race' and refuge provision in Britain', Gender, Place and Culture, 11, 375-97.

BUITELAAR, E. (2009), 'Zoning, more than just a tool: explaining Houston's regulatory practice', European Planning Studies, 17, 1049-65.

CAMERON, J. and GRANT-SMITH, D. (2014), 'Putting people in planning: participatory democracy, inclusion and power', in J. Byrne, N. Sipe and J. Dodson (eds), Australian Environmental Planning: Challenges and Future Prospects, Abingdon, Routledge, 197-205.

CAMERON, J. and GRANT-SMITH, D. (2005), 'Building citizens: participatory planning practice and a transformative politics of difference', Urban Policy and Research, 23, 21-36.

CASS, N. and WALKER, G. (2009), 'Emotion and rationality: the characterisation and evaluation of opposition to renewable energy projects', Emotion, Space and Society, 2, 62-69.

CONVERY, I., MORT, M., BAILEY, C. and BAXTER, J. (2007), 'Role of stress in front line workers during the 2001 Foot and Mouth Disease epidemic: the value of therapeutic spaces', The Australasian Journal of Disaster and Trauma Studies 2, http://www.massey.ac.nz/ trauma/issues/2007-2/convery.htm (accessed August 2014).

CONVERY, I., MORT, M., BAXTER, J. and BAILEY, C. (2008), Animal Disease and Human Trauma: Emotional Geographies of Disaster, Hampshire, Palgrave Macmillan. 
DAVIDSON, J., BONDI, L. and SMITH, M. (eds) (2005), Emotional Geographies, Hampshire, Ashgate.

DAVIDSON, J. and MILLIGAN, C. (2004), 'Embodying emotion sensing space: introducing emotional geographies', Social and Cultural Geography, 5, 523-32.

DAVIES, S. R., SELIN, C., GANO, G. and PEREIRA, Â. G. (2012), 'Citizen engagement and urban change: three case studies of material deliberation', Cities, 29, 351-57.

DAVOUDI, S. (2012), 'The legacy of positivism and the emergence of interpretive tradition in spatial planning', Regional Studies, 46, 429-41.

DAYA, S. and WILKINS, N. (2013), 'The body, the shelter, and the shebeen: an affective geography of homelessness in South Africa', Cultural Geographies, 20, 357-78.

DUNN, K. (2004), 'Islam in Sydney: contesting the discourse of absence', The Australian Geographer, 35, 333-53.

DUNN, K.M., KLOCKER, N. and SALABAY, T. (2007), 'Contemporary racism and Islamaphobia in Australia: racializing religion', Ethnicities, 7, 564-89.

FARBOTKO, C. and MCGREGOR, H. V. (2010), 'Copenhagen, climate science and the emotional geographies of climate change', Australian Geographer, 41, 159-66.

FERREIRA, A. (2013), 'Emotions in planning practice: a critical review and a suggestion for future developments based on mindfulness', Town Planning Review, 84, 703-19.

FISCHER, F. (2003), Reframing Public Policy: Discursive Politics and Deliberative Practices, Oxford, Oxford University Press.

FISCHER, F. (2009), 'Policy deliberation: confronting subjectivity and emotional expression', Critical Policy Studies, 3, 407-20.

FISCHLER, R. (2000), 'Communicative planning theory: a Foucauldian assessment', Journal of Planning Education and Research, 19, 358-68.

FORESTER, J. (1987), 'Planning in the face of conflict: negotiation and mediation strategies in local land use regulation', Journal of the American Planning Association, 53, 303-14.

FORESTER, J. (1999), The Deliberative Practitioner: Encouraging Participatory Planning Processes, Cambridge, MA, The MIT Press.

FORESTER, J. (2012), 'Argument, power and passion in planning practice', in S. J. Mandelbaum, L. Mazza and R. W. Burchell (eds), Explorations in Planning Theory, Piscataway, Transaction Publishers, 241-62.

FREIBERG, A. and CARSON, W. G. (2009), 'Evidence, emotion and criminal justice: the limits to evidence-based policy', (paper presented at the 40th Anniversary Symposium of the New South Wales Bureau of Crime Statistics and Research, Sydney). 
FRIEDMANN, J. (1998), 'Planning theory revisited', European Planning Studies, 6, 245-53.

FRIEDMANN, J. (2011), Insurgencies: Essays in Planning Theory, Oxon, Routledge.

GERBER, J. (1997), 'Beyond dualism: the social construction of nature and the natural and social construction of human beings', Progress in Human Geography, 21, 1-17.

GILLROY, J. M. and BOWERSOX, J. (2002), 'Introduction: the roots of moral austerity in environmental policy discourse', in J. M. Gillroy and J. Bowersox (eds), The Moral Austerity of Environmental Decision Making: Sustainability, Democracy, and Normative Argument in Policy and Law, Durham, Duke University Press, 1-22.

GOLDMAN, R. (2004), 'Circumcision policy: a psychosocial perspective', Paediatric Child Health, 9, 630-33.

GORMAN-MURRAY, A. (2010), 'An Australian feeling for snow: towards understanding cultural and emotional dimensions of climate change', Cultural Studies Review, 16, 60-81.

GRANT-SMITH, D. (2011), Regulating the Unspeakable: A Policy Story of Boaters, Floaters, Voters and Matter Out of Place, (PhD Thesis), Griffith University.

HEAD, B. (2010), 'Evidence-based policy: principles and requirements', Strengthening Evidence based Policy in the Australian Federation Volume 1: Roundtable Proceedings, Canberra, Australian Productivity Commission.

HEALEY, P. (1996), 'The communicative turn in planning theory and its implications for spatial strategy formations', Environment and Planning B, 23, 217-34.

HEALEY, P. (2009), 'The pragmatic tradition in planning thought', Journal of Planning Education and Research, 28, 277-92.

HEALEY, P. (2010), Making Better Places: The Planning Project in the Twenty-First Century, Hampshire, Palgrave MacMillan.

HEIMTUN, B. (2010), 'The holiday meal: eating out alone and mobile emotional geographies', Leisure Studies, 29, 175-92.

HEPWORTH, M. (2005), 'Ageing and the emotions: framing old age in Victorian painting', in Davidson et al. (eds), 177-90.

HILLIER, J. (1995), 'The unwritten law of planning theory: common sense', Journal of Planning Education and Research, 14, 292-96.

HILLIER, J. and GUNDER, M. (2005), 'Not over your dead bodies! A Lacanian interpretation of urban planning discourse and practice', Environment and Planning A, 37, 1049-66.

HOCH, C. (1984), 'Doing good and being right: the pragmatic connection in planning theory', Journal of the American Planning Association, 50, 335-45.

HOCH, C. (2006), 'Emotions and planning', Planning Theory and Practice, 7, 367-82. 
JONES, H. (2013), Negotiating Cohesion, Inequality and Change: Uncomfortable Positions in Local Government, Bristol, Policy Press.

JONES, O. (2005), 'An ecology of emotion, memory, self and landscape', in Davidson et al. (eds), 205-18.

KNOPP, L. (2007), 'On the relationship between Queer and Feminist geographies', The Professional Geographer, 59, 47-55.

LIPSKY, M. (2010), Street-Level Bureaucracy: Dilemmas of the Individual in Public Service, $30^{\text {th }}$ Anniversary Expanded Edition, New York, Russell Sage Foundation.

MARONEY, T. A. (2006), 'Law and emotion: a proposed taxonomy of an emerging field', Law and Human Behaviour, 30, 119-42.

MAGILL, A.W. (1991), 'Barriers to effective public interaction: helping natural resource professionals adjust their attitudes', Journal of Forestry, 89, 16-18.

McGUIRK, P. M. (2001), 'Situating communicative planning theory: context, power, and knowledge', Environment and Planning A, 33, 195-217.

MEYER, M. A. (2008), 'Indigenous and authentic: Hawaiian epistemology and the triangulation of meaning', in N. K. Denzin, Y. S. Lincoln and L. T. Smith (eds), Handbook of Critical and Indigenous Methodologies, Thousand Oaks, SAGE Publications, 217-32.

MORGAN, E. and GRANT-SMITH, D. (2014), 'Tales of science and defiance: the case for colearning and collaboration in bridging the science/emotion divide in water recycling debates', Journal of Environmental Planning and Management, 58, 1-19.

MORRISON, C.-A. (2010), 'Home is Where the Heart is': Everyday Geographies of Young Heterosexual Couples' Love in and of Homes, (PhD Thesis), The University of Waikato.

MYSAK, M. (2010), The Environmental is Political: Exploring the Geography of Environmental Justice, (PhD Thesis), University of North Texas.

NAIRN, K. and HIGGINS, J. (2011), 'The emotional geographies of neoliberal school reforms: spaces of refuge and containment', Emotion, Space and Society, 4, 180-86.

PAPAYANIS, M. A. (2000), 'Sex and the revanchist city: zoning out pornography in New York', Environment and Planning D: Society and Space, 18, 341-53.

PRIOR, J. H. and CROFTS, P. (2012), 'Effects of sex premises on neighbourhoods: residents, local planning and the geographies of a controversial land use', New Zealand Geographer, 68, $130-40$.

PRITCHARD, A., MORGAN, N. and SEDGLEY, D. (2002), 'In search of lesbian space? The experience of Manchester's gay village', Leisure Studies, 21, 105-23.

RITTEL, H. W. J. and WEBBER, M. M. (1973), 'Dilemmas in a general theory of planning', Policy Sciences, 4, 155-69. 
RYDIN, Y. (2007), 'Re-examining the role of knowledge within planning theory', Planning Theory, 6, 52-68.

SAARIKOSKI, H. (2002), 'Naturalized epistemology and dilemmas of planning practice', Journal of Planning Education and Research, 22, 3-14.

SANDERCOCK, L. (1998a), 'The death of modernist planning: radical praxis for a postmodern age', in M. Douglass and J. Friedmann (eds), Cities for Citizens: Planning and the Rise of Civil Society in a Global Age, Chichester, John Wiley, 163-84.

SANDERCOCK, L. (1998b), Towards Cosmopolis: Planning for Multicultural Cities, Chichester, John Wiley.

SANDERCOCK, L. (2000), 'When strangers become neighbours: managing cities of difference', Planning Theory and Practice, 1, 13-30.

SANDERCOCK, L. (2001), 'Out of the closet: the importance of stories and storytelling in planning practice', Planning Theory and Practice, 4, 11-28.

SANDERCOCK, L. and FORSYTH, A. (2005), 'A gender agenda: new directions for planning theory', in S. S. Fainstein and L. J. Servon (eds), Gender and Planning: A Reader, New Brunswick, Rutgers University Press, 67-85.

SCHÖN, D. (1983), The Reflective Practitioner: How Professionals Think in Action, New York, Basic Books.

SULTANA, F. (2011), 'Suffering for water, suffering from water: emotional geographies of resource access, control and conflict', Geoforum, 42, 163-72.

TEWDWR-JONES, M. (2002), 'Personal dynamics, distinctive frames and communicative planning', in P. Allmendinger and M. Tewdwr-Jones (eds), Planning Futures: New Directions for Planning Theory, London, Routledge, 65-92.

TEWDWR-JONES, M. and THOMAS, H. (1998), 'Collaborative action in local plan-making: planners' perceptions of "planning through debate", Environment and Planning B, 25, 217-44.

THIEN, D. (2005), 'Intimate distances: considering questions of "Us", in Davidson et al. (eds), 191-204.

THROGMORTON, J. A. (2003), 'Planning as persuasive storytelling in a global-scale web of relationships', Planning Theory, 2, 125-51.

TUAN, Y.-F. (1977), Space and Place: The Perspective of Experience, London, Edward Arnold.

VAHED, Y. and VAHED, G. (2014), 'The development impact of mosque location on land use in Australia: a case study of Masjid al Farooq in Brisbane', Journal of Muslim Minority Affairs, 34, 66-81.

VAN HULST, M. (2012), 'Storytelling, a model of and a model for planning', Planning Theory, 11, 299-318. 
VINING, J. (1992), 'Environmental emotions and decisions: a comparison of the responses and expectations of forest managers, an environmental group, and the public', Environment and Behavior, 24, 3-34.

WATKINS, M. (2011), 'Teachers' tears and the affective geography of the classroom', Emotion, Space and Society, 4, 137-43.

WINGFIELD, A. H. (2010), 'Are some emotions marked 'whites only'? Racialized feeling rules in professional workplaces', Social Problems, 57, 251-68.

WRIGHT, M. W. (2010), 'Gender and geography II: bridging the gap - feminist, queer, and the geographical imaginary', Progress in Human Geography, 34, 56-66.

WRIGHT, S. (2012), 'Emotional geographies of development', Third World Quarterly, 33, 1113-27.

YOUNG, I. M. (1995), 'Communication and the Other: beyond deliberative democracy', in M.Wilson and A. Yeatman (eds), Justice and Identity: Antipodean Practices, St Leonards, Allen and Unwin, 134-52.

ZEMBYLAS, M. (2011), 'Investigating the emotional geographies of exclusion at a multicultural school', Emotion, Space and Society, 4, 151-59. 